\title{
Connexin43 and Bergmann glial gap junctions in cerebellar function
}

\section{Mika Tanaka ${ }^{1 *}$, Kazuhiko Yamaguchi ${ }^{1}$, Tetsuya Tatsukawa ${ }^{1}$, Martin Theis ${ }^{2,3}$, Klaus Willecke ${ }^{3}$ and Shigeyoshi Itohara ${ }^{1 *}$}

1 RIKEN Brain Science Institute (BSI), Japan

2 Institute for Genetics, University of Bonn, Germany

3 Institute of Cellular Neurosciences, University of Bonn, Germany

Connexin43 (Cx43), a major component of astrocytic gap junctions, is abundantly expressed in Bergmann glial cells (BGCs) in the cerebellum, but the function of $C \times 43$ in BGCs is largely unknown. BGCs are specialized astrocytes closely associated with Purkinje cells. Here, we review our recent studies of the role of $\mathrm{Cx} 43$ in gap junctional coupling between BGCs and in cerebellar function. We generated $C \times 43$ conditional knockout mice with an S100b-Cretransgenic line (Cx43/f/t:S100b-Cre), in which there was a significant postnatal loss of $\mathrm{Cx} 43$ in BGCs and cerebellar astrocytes. Gap junctional coupling between BGCs measured by dye coupling was virtually abolished in $C \times 43^{\text {th }}$ ff: S100b-Cre mice. Electrophysiologic and behavioral analyses suggested that $\mathrm{C} \times 43$-mediated gap junctions and $\mathrm{C} \times 43$ hemichannels in BGCs are not necessary for the neuron-glia interactions required for cerebellum-dependent motor coordination and motor learning. These findings raise questions regarding the regional differences in the impact of the loss of $\mathrm{C} \times 43$ in the brain.

Keywords: connexin43, gap junction, astrocyte, Bergmann glia, conditional knockout mouse

\section{INTRODUCTION}

Astrocytes, the most abundant cell type in the mammalian brain, are extensively coupled by gap junctions (Giaume and McCarthy, 1996) through which ionic and metabolic homeostasis (e.g., spatial buffering of $\mathrm{K}^{+}$and glutamate) is maintained, and electrical coupling and intercellular signaling (e.g., $\mathrm{Ca}^{2+}$ wave) occur (Ransom and Ye, 2005). The gap junction channel is formed by two hemichannels, each of which comprises six protein subunits called connexins. Connexin43 (Cx43), the major constituent of astrocytic gap junctions, is abundantly expressed in astrocytes throughout the brain (Dermietzel et al., 1989; Giaume and McCarthy, 1996). Cx43 knockout in mice causes early postnatal lethality due to heart malfunction (Reaume et al., 1995), and therefore conditional knockout (CKO) of Cx43 in mice with Cre/loxP system has been used to study the function of $\mathrm{Cx} 43$ in the brain.
The first $C x 43 \mathrm{CKO}$ mice, exhibiting the loss of $\mathrm{Cx} 43$ essentially in all astrocytes in the brain, were generated using the $C x 43$ floxed allele $\left(C x 43^{f}\right)$ in which the $C \times 43$ coding sequence is flanked by two loxP sites (Theis et al., 2001), in combination with a Cre transgenic line under the control of the human glial fibrillary acidic protein promoter (hGFAP-Cre) (Theis et al., 2003). Cx43 $3^{\text {fl }}$ ${ }^{f l}$ :hGFAP-Cre mice are viable and show no histologic abnormalities in the brain (Theis et al., 2003), but exhibit several features in situ and in vivo that are related to brain physiology and/or function, as follows: [in situ] accelerated hippocampal spreading depression (Theis et al., 2003) and impaired $\mathrm{Ca}^{2+}$ wave propagation in neocortex (Haas et al., 2006); [in vivo] enhanced locomotor activity (Theis et al., 2003); increased exploratory behavior, impaired motor capacity, and changes in brain acetylcoline level (Frisch et al., 2003); and increased apoptosis and inflammation after 


\section{Astrocytic gap junction}

Most of astrocytes are coupled by gap junction and form functional

syncytium in the brain.

Conditional knockout (CKO) mouse Tissue- or cell type-specific knock out of genes can be generated in mice by using Cre/loxP system, which requires genomic region flanked by two loxP sites (floxed allele) and tissue- or cell type-specific expression of Cre recombinase. Cre-mediated excision deletes the genomic region flanked by two loxP sites.

Bergmann glial cells (BGCs) Specialized form of astrocytes in the cerebellum, with their somata located in the Purkinje cell layer and processes extending through the molecular layer of the cerebellum.

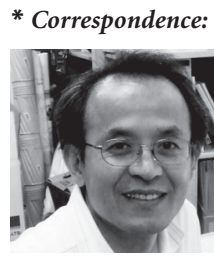

Dr. Shigeyoshi Itohara has studied the role of astrocyte-neuron interactions in higher brain function using a series of mutant mice with selective astrocyte deficits. His research has now expanded to examine the roles of transneuronal ligand-receptor pairs, specifically netrin-G1/G2 and NGL1/2, as well as the roles of the neuronal circuits controlled by these ligand-receptor pairs. sitohara@brain.riken.jp cerebral ischemia (Nakase et al., 2004). In addi-

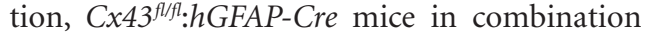
with a null mutation of $C \times 30$, another astrocytic connexin, have impaired spatial $\mathrm{K}^{+}$buffering and a reduced threshold for the generation of epileptiform events in the hippocampus in situ (Wallraff et al., 2006). Figiel et al. (2007) showed that deletion of $C x 43$ in cortical astrocytes causes a loss of glutamate transporter GLT-1. Recently, Lin et al. (2008) reported that $C x 43^{f l f f l}:$ GFAP-Cre mice are insensitive to hypoxic preconditioning, and in this case $\mathrm{Cx} 43$ functions as hemichannels that serve as a pathway for the efflux of ATP. Although these findings successfully demonstrated the involve- ment of astrocytic Cx43 in brain physiology and/or function, questions remain regarding the role of $\mathrm{Cx} 43$ in the cerebellum.

Bergmann glial cells (BGCs) are unipolar astrocytes that extend long processes across the molecular layer of the cerebellum (Figures 1A,B). BGC processes form intimate structural relationships with the dendrites of Purkinje cells (Figures 1B,C) (Grosche et al., 2002; Yamada and Watanabe, 2002), which are inhibitory neurons that act as the sole source of output from the cerebellar cortex. The processes of mature BGCs surround the synapses on Purkinje cells that are formed with glutamatergic excitatory axon parallel fibers and climbing
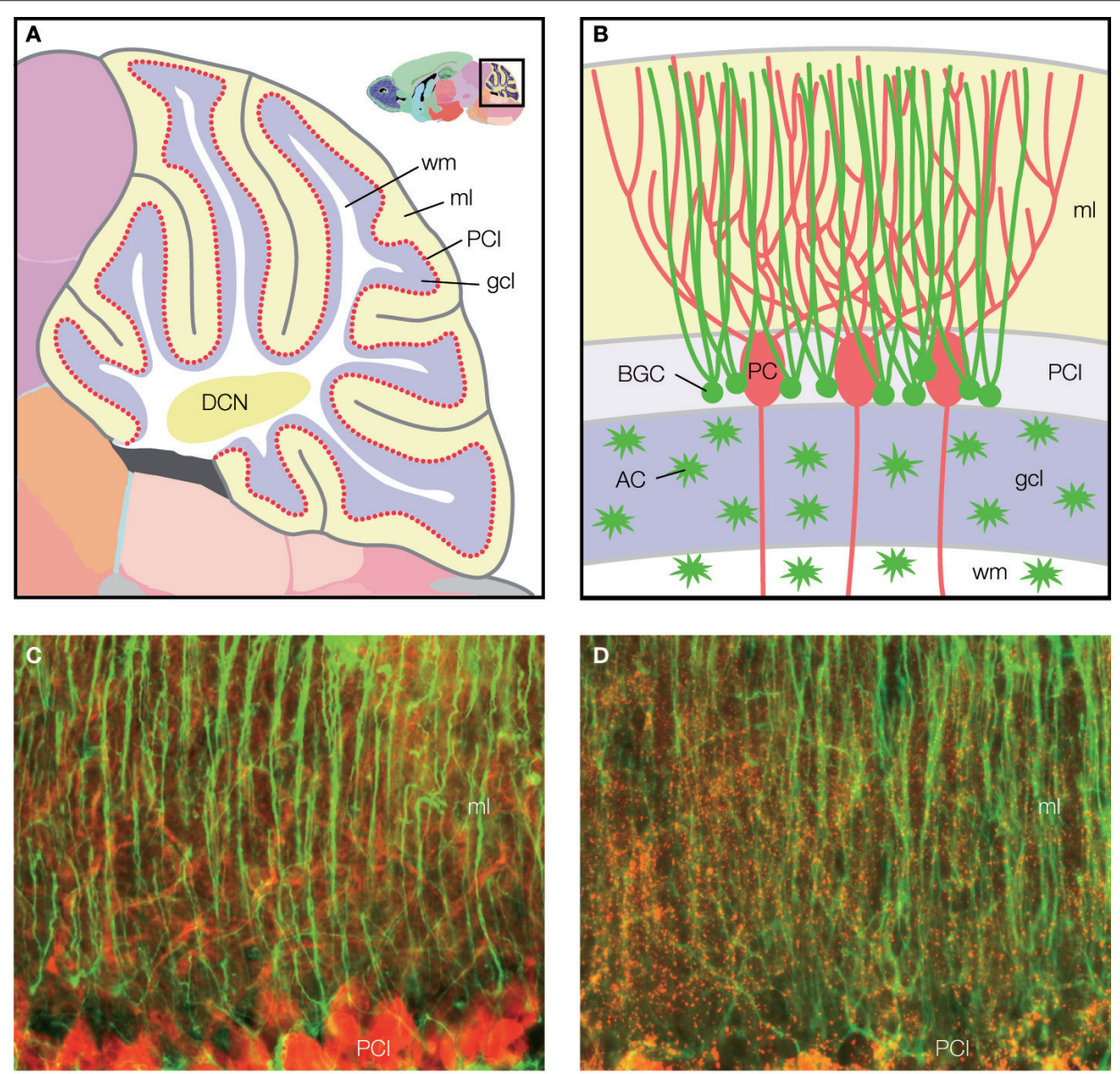

Figure 1 | Structure of the cerebellum and cerebellar molecular layer in mice. (A,B) Schematic illustration of the structure of the cerebellum in mice. (A) Parasagittal view of mouse cerebellum. The boxed region (upper right) is magnified. wm, white matter; $\mathrm{ml}$, molecular layer; PCl, Purkinje cell layer; gcl, granule cell layer; DCN, deep cerebellar nucleus. Figures are modified from Allen Mouse Brain Atlas [Internet]. Seattle (WA): Allen Institute for Brain Science. (C)2008. Available from: http//www.brain-map.org. (B) Cell bodies of Bergmann glial cells (BGC) are localized in the Purkinje cell layer (PCl), where somata of Purkinje cells (PC) align. In the molecular layer (ml), BGC processes associate closely with PC dendrites. Cerebellar astrocytes (AC) are present in the granule cell layer (gcl) and white matter (wm). (C,D) Double immunofluorescence analysis of parasagittal sections of the cerebellum from Cx43 ${ }^{\mathrm{fl} / 4}$ mice (1.5-month-old) that served as controls in Tanaka et al. (2008). (C) GFAP (green)-positive BGC processes show intimate structural relationships with calbindin-D (red)-positive PC dendrites in the molecular layer. Modified and reproduced from Tanaka et al. (2008). Front. Behav. Neurosci. 2, 1. (D) GFAP (green)-positive BGC processes are positive for Cx43 (red). Scale bar, $50 \mu \mathrm{m}$ 
fibers (Palay and Chan-Palay, 1974; Spacek, 1985). Extensive gap junctional coupling is observed in mature BGC processes (Clark and Barbour, 1997; Müller et al., 1996) where Cx43 is abundantly expressed (Figure 1D)(Nagy et al., 2001), but the role of $\mathrm{Cx} 43$ is largely unknown.

To investigate the role of $\mathrm{Cx} 43$ in cerebellar function, we constructed a new Cx43 CKO model with temporal and regional specificity of a Cre-mediated recombination directed to the cerebellum (Tanaka et al., 2008), as deficits in other brain areas, e.g., striatum, can also lead to impaired motor coordination (Blundell et al.,

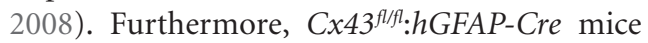
generated on a different genetic background exhibit cellular disorganization of the cortex, hippocampus, and cerebellum, accompanied by ataxia and motor deficits (Wiencken-Barger et al., 2007), suggesting the importance of controlling the onset and regional specificity of Cx43 CKO to study neuron-glia interactions in the adult cerebellum. Using a new Cx43 CKO model, we recently investigated the contribution of $\mathrm{Cx} 43$ to gap junctional coupling between BGCs, and examined whether Cx43 in BGCs, either as a gap junction channel or a hemichannel, plays an important role in cerebellar functions via Purkinje cell-BGC interactions.

\section{GENERATION OF A NEW CX43 CKO MICE WITH EFFICIENT POSTNATAL RECOMBINATION IN BGCS AND CEREBELLAR ASTROCYTES MEDIATED BY S100b-Cre TRANSGENE}

First we generated a new Cre transgenic line that can be used to make Cx43 CKO mice suitable for studying cerebellar functions (Tanaka et al., 2008). S100B is an EF-hand-type protein expressed primarily in astrocytes in the mammalian central nervous system (Boyes et al., 1986; Haan et al., 1982; Van Eldik et al., 1984). In rodents, the pattern of $S 100 b$ expression shows a rostral-caudal gradient during postnatal development with robust expression in the BGCs in the cerebellum (Landry et al., 1989). The generation of a transgenic mouse line using a 5.4-kb genomic sequence of $S 100 b$ to drive Cre recombinase (S100b-Cre) led to efficient deletion of $C x 43^{f l}$ in the cerebellum (Figure 2A), which can be monitored by $\beta$-galactosidase expression with a nuclear localization signal under control of the $C \times 43$ promoter upon Cre-mediated recombination of the floxed Cx43 coding region (Theis et al., 2003). Since $\beta$-galactosidase is expressed instead of $\mathrm{Cx} 43$, reporter gene expression marks those cells which have lost $\mathrm{Cx} 43$ expression driven by the $C \times 43^{f l}$ allele. The recombination pattern of $C \times 43^{f l+}$ :
S100b-Cre mice with a rostral-caudal gradient as indicated by lacZ staining (Figure 2A, upper left), was very similar to that of the endogenous $S 100 \mathrm{~b}$ pattern during postnatal development (Landry et al., 1989). Immunohistochemical analysis of the $C \times 43^{f l /+}: S 100 b$-Cre mice revealed that nuclear $\beta$-galactosidase immunoreactivity was located in BGCs in the Purkinje cell layer, and in cerebellar astrocytes in the granule cell layer and white matter, all of which were S100B-positive and NeuN-negative (Figure 2B).

$S 100 b$-Cre-mediated recombination of $C x 43^{f}$ in the cerebellum began and progressed during postnatal development (Figure 2C). Excision

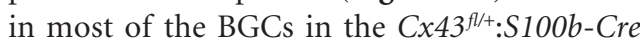
mice was completed by P28 (Figure 2C). The results obtained using different reporter strains consistently indicated that $S 100 b$-Cre-mediated recombination in the cerebellum was restricted to the BGCs and cerebellar astrocytes and did not occur in Purkinje cells or granule cells (Tanaka et al., 2008). It is therefore likely that the efficient and cell type-specific recombination in BGCs and cerebellar astrocytes in the adult cerebellum is due to the postnatal onset of S100b-Cre-mediated recombination in the precursors of those cells. The temporal and spatial Cre-mediated recombination pattern induced by $S 100 b$-Cre is markedly different from that of GFAP-Cre lines using either the human or mouse Gfap promoter, in which Cre-mediated recombination occurs in neural progenitors of prenatal embryos, resulting in widespread recombination in neurons and glial cells (Bajenaru et al., 2002; Casper and McCarthy, 2006; Garcia et al., 2004; Kwon et al., 2001; Zhuo et al., 2001). Thus, our transgenic S100b-Cre line appears to be an ideal tool for studying glial function in the cerebellar molecular layer and/or granule cell layer in postnatal late developmental stages and adulthood in mice.

\section{A CRUCIAL ROLE FOR CX43 IN GAP JUNCTIONAL COUPLING BETWEEN BGCS}

The S100b-Cre transgenic line was then used to generate $C x 43 \mathrm{CKO}$ (Cx43 $\left.3^{f l f l}: S 100 b-C r e\right)$ mice, to examine the role of $\mathrm{Cx} 43$ in the postnatal cerebellum, particularly in the Purkinje cell-BGC interactions in the cerebellar molecular layer. In $C \times 43^{f l /}$ ${ }^{f l}:$ S100b-Cre mice, a loss of Cx43 was evident in most of the cerebellar astrocytes and in virtually all of the BGCs in the cerebellar molecular layer in the adult (Figure 3A). No compensatory changes were observed in the expression of $\mathrm{Cx} 30$, another connexin expressed in astrocytes and BGCs (Nagy et al., 1999, 2001), in the cerebellum of Cx43 fl ${ }^{f l}$ :S100b-Cre mice (Tanaka et al., 2008). The cere- 


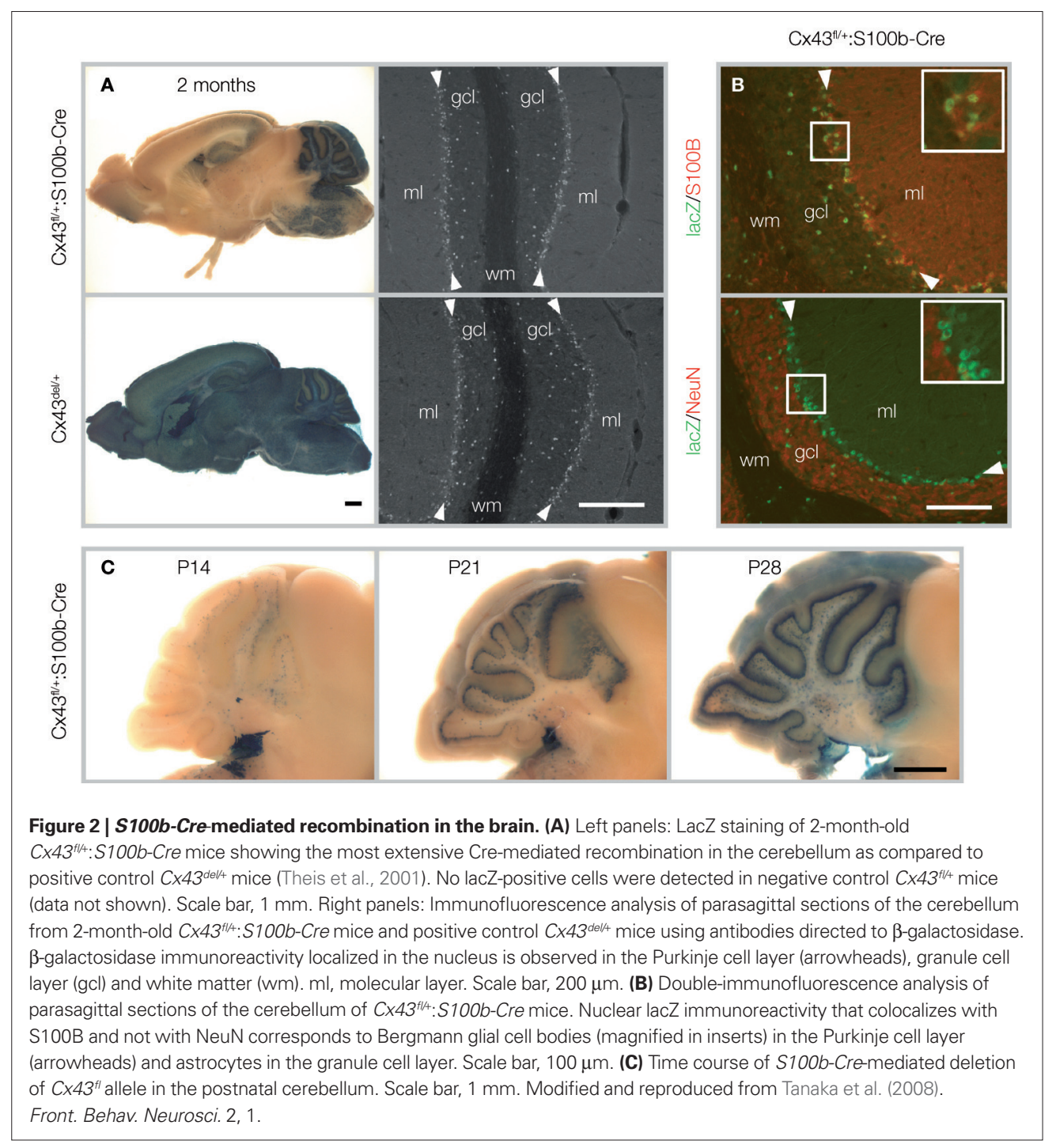

Eyeblink conditioning A form of classical conditioning in which animals are trained to blink in response to a tone. bellar architecture of the $C x 43^{\text {flff: }}:$ 100b-Cre mice was normal, including normal morphology of both the BGCs and Purkinje cells (Tanaka et al., 2008), suggesting that $C x 43$ does not have a key role in the structural support of BGCs or cerebellar astrocytes in the late cerebellar developmental stages or adulthood.

We then investigated whether the loss of $\mathrm{Cx} 43$ in the BGCs affected gap junctional coupling in situ. Dye coupling experiments using Lucifer yellow demonstrated that $\mathrm{Cx} 43$ contributes significantly to gap junctional coupling between BGCs (Figures 3B,C). The magnitude of Lucifer yellow dye coupling was closely related with the amount of $\mathrm{Cx} 43$ protein, which was reduced in $C \times 43^{\text {fl/f }}$ mice to approximately $30 \%$ that of wild-

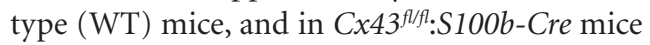
to approximately $10 \%$ that of WT mice (Tanaka et al., 2008).

\section{DISPENSABLE ROLE OF CX43 IN BGCs IN CEREBELLAR FUNCTION}

The failure of glutamate uptake at Purkinje cell synapses by the glutamate transporters GLAST and GLT-1 expressed in BGCs results in motor discoordination in mice (Rothstein et al., 1996; Watase et al., 1998), which most likely is caused by the multiple innervation of Purkinje cell by climbing fibers (Watase et al., 1998). Defects in Gfap KO mice (Shibuki et al., 1996), such as impaired cerebellar long-term depression (LTD) at the parallel fiber (PF)-Purkinje cell (PC) synapses and impaired motor learning "eyeblink conditioning", may be caused by enhanced glutamate uptake through the upregulation of GLT-1 in the cerebellum (Hughes et al., 2004). Importantly, the deletion of $C x 43$ in cortical astrocytes is associated with a loss in GLT-1 expression (Figiel et al., 2007). In addition, gap junctions are permeable to 

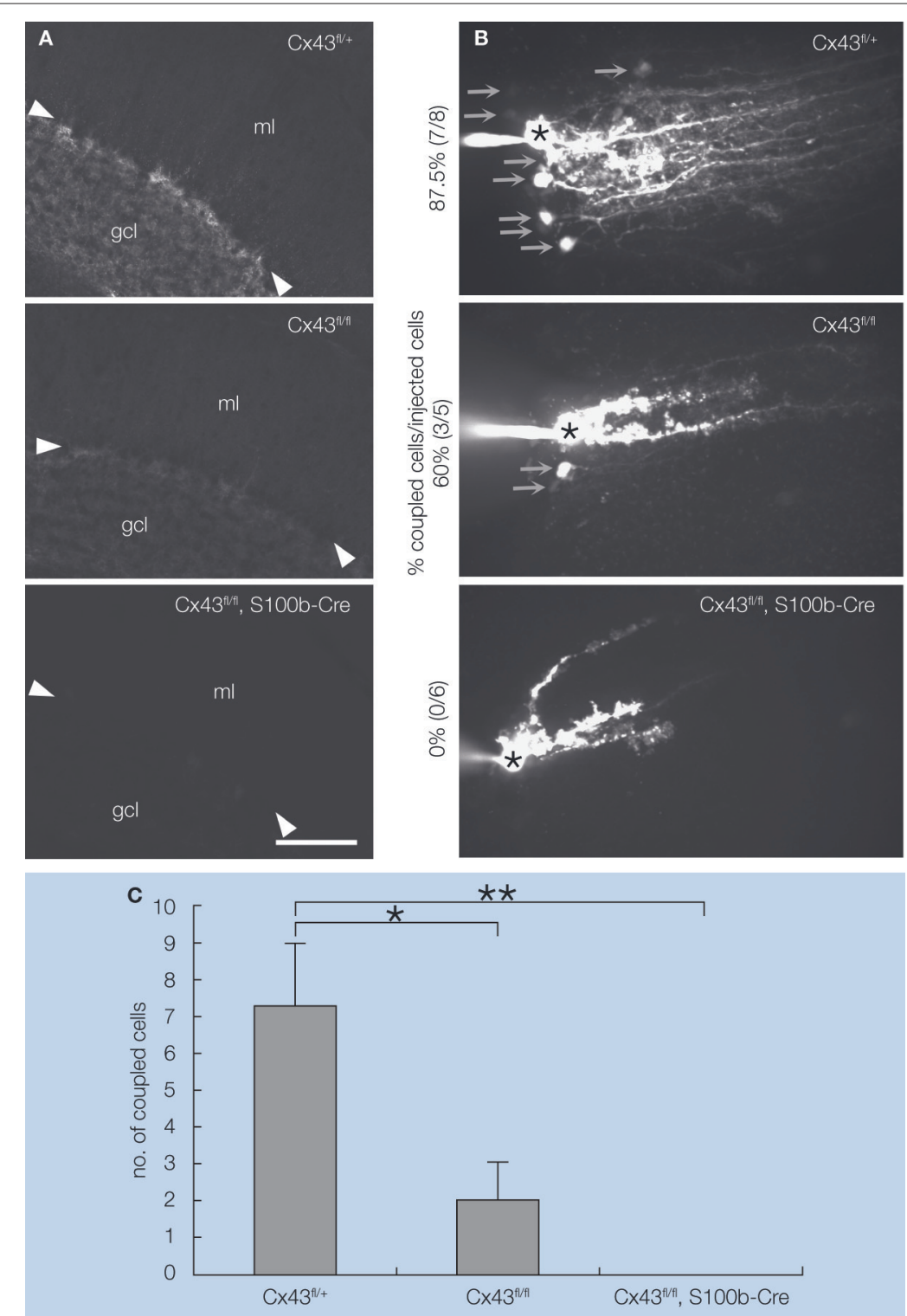

Figure 3 | Extent of S100b-Cre-mediated loss of Cx43 and Lucifer yellow coupling between

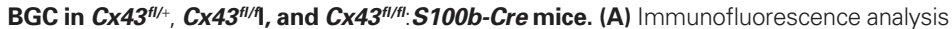

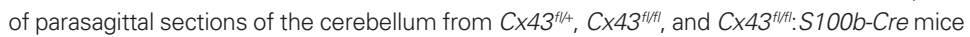
(2.5-month-old) using antibodies directed to Cx43. Arrowheads indicate Purkinje cell layer. gcl, granule cell layer; $\mathrm{ml}$, molecular layer. Scale bar, $100 \mu \mathrm{m}$. (B) Intercellular Lucifer yellow transfer in BGC in parasagittal cerebellar slices from $C \times 43^{f / / 4}, C \times 43^{f / f t}$, and $C \times 43^{f / f t /: S 100 b-C r e ~ m i c e ~}$ (3.5-month-old) after Lucifer yellow injection into one BGC soma. The asterisk indicates a dye-injected BGC cell body. Arrows indicate representative dye-coupled BGC cell bodies. (C) Average numbers of dye-stained neighboring cells when processes of injected cells were stained as shown in (B) ( $n=8$ for $C \times 43^{f / / 4}, n=5$ for $C \times 43^{f / f / t}$, and $n=6$ for $C \times 43^{f / f / t l}:$ S100b-Cre). Error bars represent SEM. ${ }^{*}, p<0.05 ;{ }^{*}{ }^{*}, p<0.01$ in ANOVA. Modified and reproduced from Tanaka et al. (2008). Front. Behav. Neurosci. 2, 1. glutamate (Goldberg et al., 1999; Hansson et al., 2000; Weber et al., 2004). Based on these reports, we postulated that $\mathrm{Cx} 43$ in BGCs is involved in two distinct cerebellar functions, motor coordination and motor learning, by regulating glutamate uptake via maintaining the expression of glutamate transporters and/or controlling the spatial buffering of glutamate through gap junctions. Alternatively, Cx43 may be required for other regulatory systems as reported for other brain regions (e.g., $\mathrm{K}^{+}$buffering through gap junctions and ATP release from hemichannels) in the cerebellum.

To determine whether the loss of $\mathrm{Cx} 43$ in BGCs affects Purkinje cell synaptic plasticity, which is substantially involved in cerebellumdependent behaviors (Ito, 2001), we analyzed the kinetic properties of basal synaptic transmission and cerebellar LTD at PF-PC synapses in slices of adult $C x 43^{f l f f}: S 100 b$-Cre cerebellum First, we stimulated parallel fibers in the middle molecular layer and recorded excitatory postsynaptic currents (EPSCs) from Purkinje cells. There were no significant differences in the basal kinetic properties of the PF-EPSCs (10-90\% rising time, $1.6 \pm 0.2$ and $1.3 \pm 0.2 \mathrm{~ms}$; $p>0.2$; decay time constant, $15.5 \pm 2.0$ and $15.6 \pm 1.3 \mathrm{~ms} ; p>0.9)$ between control $(n=8)$ and $C \times 43^{f l f l t}: S 100 b$-Cre $(n=9)$ cells (Figure 4A). To induce LTD of PF-EPSCs, we administered PF-stimulation with simultaneous somatic depolarization of Purkinje cells (140 ms, - 70 to $+10 \mathrm{mV}$ ) at $1 \mathrm{~Hz}$ for $5 \mathrm{~min}$ (Koekkoek et al., 2005). The conjunctive stimuli induced a significant decrease in the amplitude of PF-EPSCs in both control $\left(C x 43^{f l /+}\right)$ and $C x 43^{f l / f l}: S 100 b$-Cre cells (Figure 4B; $p<0.01$ for each). The magnitude of LTD in the $C \times 43^{f l f l}: S 100 b$-Cre cells measured during a 25 - to $30-\mathrm{min}$ period after stimulation was comparable with that in the control cells (Tanaka et al., 2008).

To study the motor behavior of $C \times 43^{f l}$ ${ }^{f l}:$ S100b-Cre mice, we first performed an open field test with 2.5-month-old control $C x 43^{f /+}$ $(n=13)$ and $C x 43^{f l f l}:$ S100b-Cre $(n=10)$ mice. The genotypes did not significantly differ in either horizontally directed locomotor activity or in time spent in the center of the open field (data not shown). We then performed a rotarod test to determine whether these mice had normal motor coordination. We trained 2.5-month-old control $C x 43^{f l+t}(n=14)$ and Cx43 flffl:S100b-Cre $(n=11)$ mice over 5 days to balance on an accelerating rotating rod (Figure 4C). Although the latency of $C x 43^{f l}$ ${ }^{f}$ :S100b-Cre mice to fall decreased slightly on the third day of training compared to that of control mice, their performance improved on the fourth and fifth days. There was no statistically significant difference in overall performance between the genotypes. There was no significant difference in the body weight of the mice used for the rotarod test (data not shown). 

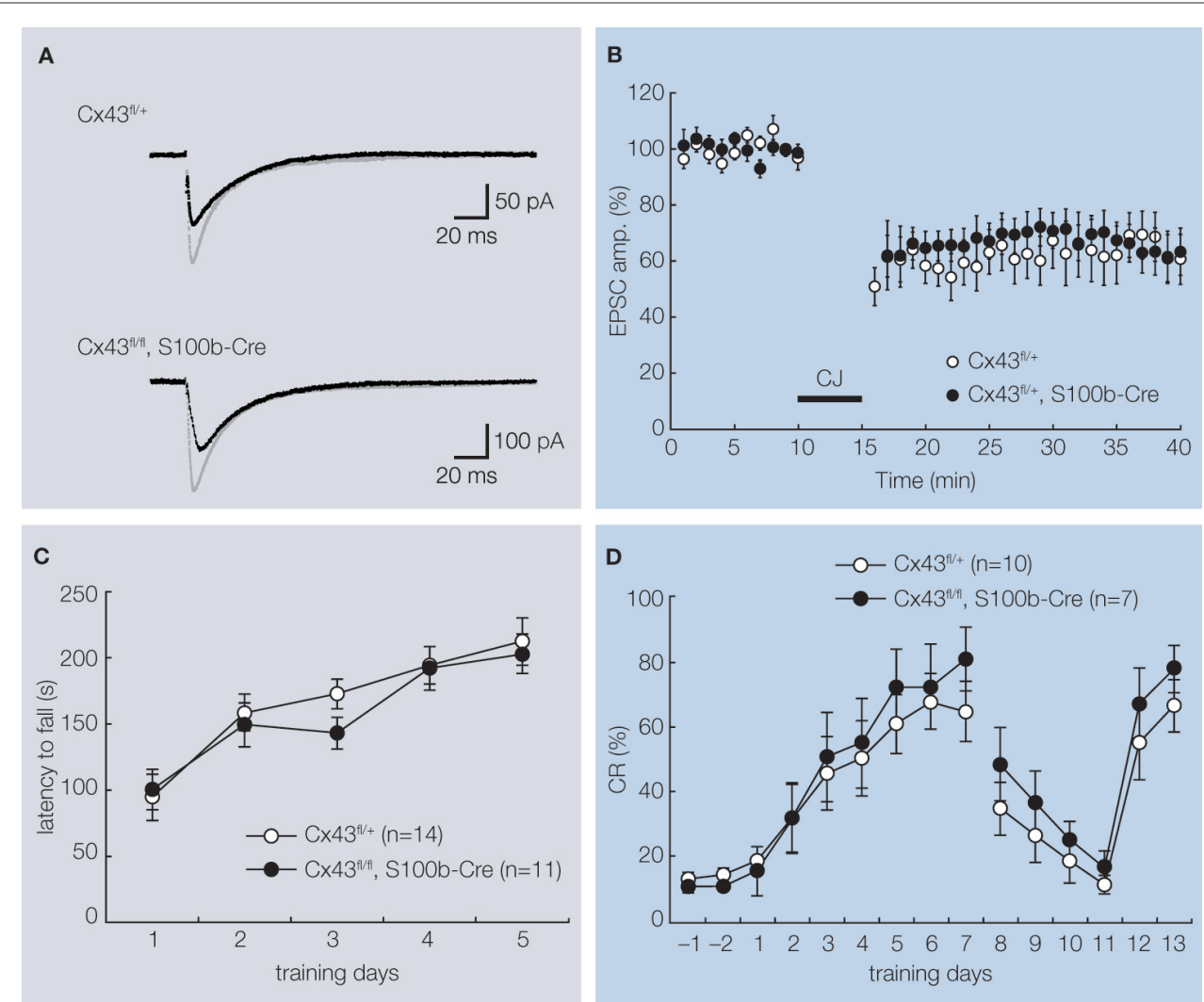

Figure 4 | Basal PF-PC EPSC, LTD induction, and behavioral analysis of control (CX43 $\left.{ }^{f /++}\right)$ and $C \times 43^{f / f l}: S 100 b-C r e$ mice. (A) A representative example of PF-EPSC before (gray) and after (black) conjunctive stimulation in $C \times 43^{f / / 4}$ and

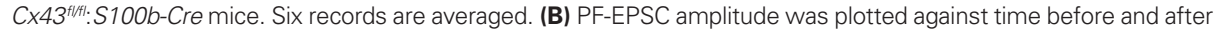
conjunctive stimulation averaged for eight cells from $8 \mathrm{C} \times 43^{\mathrm{fl} / \mathrm{t}}$ mice or for nine cells from $8 \mathrm{Cx} 43^{\mathrm{fl} / \mathrm{fl}}$ :S100b-Cre mice. Each point represents the average of three successive responses acquired for $1 \mathrm{~min}$ at $0.05 \mathrm{~Hz}$. Bar indicates the period of conjunctive stimulation (CJ). (C) Accelerating rotarod test. The mean ( \pm SEM) time an animal remained on an accelerating rod (6-40 rpm) during training with one trial per day for five consecutive days ( $n=14$ for $C \times 43^{f / / 4}$, and $n=11 \mathrm{for} C \times 43^{\mathrm{fl} /}$ ${ }^{f l}$ :S100b-Cre). (D) Delay eyeblink conditioning. The mean ( \pm SEM) conditioned response (CR) percentage of $C \times 43^{f / 4}$

$(n=10)$ and $C \times 43^{f / f f l}: S 100 b-C r e(n=7)$ during acquisition (days $\left.1-7\right)$, extinction (days 8-11), and relearning (days 12-13) sessions. Modified and reproduced from Tanaka et al. (2008). Front. Behav. Neurosci. 2, 1.

The impact of the loss of Cx43 in BGCs and the reduction of $\mathrm{Cx} 43$ in astrocytes in the deep cerebellar nuclei (data not shown) on delay eyeblink conditioning were then evaluated in 3 - to 3.5-month-old control $C x 43^{f /+}(n=10)$ and $C x 43^{f l f l}: S 100 b-C r e(n=7)$ mice. Eyeblink conditioning is a task in which an animal learns to associate a conditioned stimulus (CS) with a noxious unconditioned stimulus (US) that elicits an eyeblink (Christian and Thompson, 2003). The memory trace for delay eyeblink conditioning, in which the preceding CS and the US terminate simultaneously, is considered to be formed in the cerebellar cortex and deep cerebellar nuclei (Attwell et al., 2002; Christian and Thompson, 2003; Mauk and Buonomano, 2004), and cerebellar LTD appears to be a neural correlate of delay eyeblink conditioning (Christian and Thompson,
2003). During eyeblink conditioning of control and $C x 43^{\text {flffl: }}: S 100 \mathrm{~b}$-Cre mice, a CS (tone $1 \mathrm{kH}$, $352 \mathrm{~ms}, 83-85 \mathrm{~dB}$ ) was paired with the US, a periorbital shock ( $100 \mathrm{~ms}, 100 \mathrm{~Hz}$ pulses). Both genotypes exhibited an increased frequency of conditioned responses during the 7-day training period (Figure 4D). There were no statistically significant differences in acquisition, extinction, or relearning kinetics of the conditioned responses, however, between control and $C x 43^{\text {fl/ }}$ fl:S100b-Cre mice (Tanaka et al., 2008).

\section{DISCUSSION AND FUTURE PERSPECTIVES}

A new model of $C \times 43$ CKO (Cx43 $\left.3^{f l f f}: S 100 b-C r e\right)$ mice in which $\mathrm{Cx} 43$ ablation occurs preferentially in the postnatal cerebellum has been developed. In contrast to previous reports of $C \times 43^{f l / f l}$ : hGFAP-Cre mice (Frisch et al., 2003; Theis et al., 2003), behav- 
ioral analyses of the $C x 43^{f l / f l}: S 100 b$-Cre mice in the present study did not reveal enhanced locomotor activity nor increased exploratory behavior in the open field test (data not shown), further suggesting limited S100b-Cre-mediated recombination of the $C \times 43^{f l}$ allele in the forebrain of Cx43 $3^{f l f l}:$ S100b-Cre mice (Figure 2A) (Tanaka et al., 2008). Cerebellum-dependent behaviors, such as motor coordination and eyeblink conditioning, were not significantly impaired in $C x 43^{f l /}$ ${ }^{f l}$ :S100b-Cre mice (Figure 4C,D), in contrast to the previously reported impairment in rotarod performance of $C x 43^{f l f l}$ :hGFAP-Cre mice (Frisch et al., 2003). The restricted nature of the $S 100 b$ Cre-mediated deletion might explain the lack of rotarod impairment in the Cx43 flfl:S100b-Cre mice, because the functions of other brain regions can also affect motor coordination (Blundell et al., 2008).

Our results suggest that $\mathrm{Cx} 43$ expressed in BGCs, either as a gap junction channel or hemichannel, is not required for glutamate uptake, $\mathrm{K}^{+}$buffering, or other regulatory mechanisms that may be involved in the Purkinje cell synaptic plasticity related to cerebellum-dependent behaviors in adult mice. These results further suggest that $\mathrm{Cx} 43$ in BGCs or, more broadly, in cerebellar astrocytes including the BGCs, do not have an essential role in the eyeblink conditioning motor learning circuit. It remains unclear, however, whether other connexins expressed in BGCs, such as Cx30 and Cx29 (Altevogt and Paul, 2004; Eiberger et al., 2006; Nagy et al., 2001), functionally compensate for the absence of Cx43. Cx30 forms functional gap junction channels that are not permeable to Lucifer yellow (Manthey et al., 2001) and is expressed in the BGCs of Cx43 fl/ ${ }^{f l}$ :S100b-Cre mice (Tanaka et al., 2008). The role of these other connexins must be clarified by studying the consequences of their combined ablation in BGCs using [Cx30--- $\left.C \times 43^{f l f f l}: S 100 b-C r e\right]$ mice or $\left[C \times 29^{-1-}, C \times 30^{---}, C \times 43^{f l f l}: S 100 b-C r e\right]$ mice.

Although mutual interactions between Purkinje cells and BGCs have been described in several reviews (Bellamy, 2006; Lopez-Bayghen et al., 2007; Metea and Newman, 2006), our results suggest that these Purkinje cell-BGC interactions are less dependent on gap junctional coupling between BGCs. The morphology of the BGCs, which forms a perpendicular array, may facilitate the spatial buffering of molecules as in the case of astrocytes in the stratum radiatum in the hippocampus (Wallraff et al., 2006). In addition, the functional independence of $\mathrm{Cx} 43$ in BGCs compared to astrocytes in other brain regions where the loss of $\mathrm{Cx} 43$ results in physiologic and/ or functional impairments (Frisch et al., 2003;
Haas et al., 2006; Theis et al., 2003) may reflect a functional heterogeneity of these astrocytic subsets located in different brain regions. For example, $\mathrm{Ca}^{2+}$ increases in BGCs restricted to microdomains (Kettenmann and Schipke, 2004) are different from the intrinsic calcium oscillations observed in hippocampal astrocytes (Fiacco and McCarthy, 2006).

Several lines of evidence indicate brain regionspecific differences in response to the knockout of astrocyte-specific genes: (1) In Gfap KO mice (Shibuki et al., 1996), glutamate uptake is reduced in association with a failure in glial transporter GLT-1 trafficking in the cortex and hippocampus, whereas glutamate uptake is enhanced in the cerebellum (Hughes et al., 2004). (2) In S100b KO mice, microarray analysis revealed alterations of different groups of genes between the hippocampus and cerebellum (Ohshima, Kim, Konishi, and Itohara, unpublished data), which might be responsible for functional impairments detected in the hippocampus (Nishiyama et al., 2002; Sakatani et al., 2007, 2008) and for the preserved cerebellar functions (Ohshima, Kim, Konishi and Itohara, unpublished data). Based on these observations, the impact of $\mathrm{Cx} 43$ knockout may be different in the cerebellum compared to other brain areas. It should be also noted that large-scale global transcriptomic alterations that compensate for the functional consequences of $C x 43$ deletion in the cerebellum may occur in the Cx43 CKO, as reported for $C x 43-1-$ astrocytes and newborn mouse brains (Iacobas et al., 2007, 2008). Our results, together with the results of others, suggest that transcriptomic alterations in $C x 43 \mathrm{CKO}$ may differ between the cerebellum and other brain areas. Further studies of Cx43 CKO mice using different $\mathrm{Cre}$ lines with region-specificity will help to elucidate the heterogeneity of astrocytic subsets in the context of their functional connections to each brain area.

\section{ACKNOWLEDGMENTS}

We thank C. Nishioka for her tireless help throughout the study, H. Nishiyama for his help in the early stage of the study, and T. Iwasato, J.S. Park, Y. Sano, and S. Nishimura-Akiyoshi for advice on the experiments; the BSI Research Resources Center for animal care and technical assistance; J. Miyazaki for the CAG-CAT-Z mice; and T. Iwasato for the CAG- $\Delta-\mathrm{Z}$ mice. This work was supported, in part, by a Grant-in-Aid for Scientific Research on Priority Areas from the MEXT, Japan (to M. Tanaka). Work in the Bonn laboratory was supported by grants of the German Research Association (SFB 400, B3 and SFB 645, B2) to K. Willecke. 


\section{REFERENCES}

Altevogt, B. M., and Paul, D. L. (2004). Four classes of intercellular channels between glial cells in the CNS. J. Neurosci. 24, 4313-4323.

Attwell, P. J., Ivarsson, M., Millar, L., and Yeo, C. H. (2002). Cerebellar mechanisms in eyeblink conditioning. Ann. N.Y. Acad. Sci. 978, 79-92.

Bajenaru, M. L., Zhu, Y., Hedrick, N. M., Donahoe, J., Parada, L. F., and Gutmann, D. H. (2002). Astrocytespecific inactivation of the neurofibromatosis 1 gene (NF1) is insufficient for astrocytoma formation. Mol. Cell Biol. 22, 5100-5113.

Bellamy, T.C.(2006). Interactions between Purkinje neurones and Bergmann glia. Cerebellum 5, 116-126.

Blundell, J., Hoang, C. V., Potts, B., Gold, S. J., and Powell, C. M. (2008). Motor coordination deficits in mice lacking RGS9. Brain Res. 1190 , 78-85.

Boyes, B. E., Kim, S. U., Lee, V., and Sung, S. C. (1986). Immunohistochemical co-localization of S-100b and the glial fibrillary acidic protein in rat brain. Neuroscience 17, 857-865.

Casper, K. B., and McCarthy, K. D. (2006). GFAP-positive progenitor cells produce neurons and oligodendrocytes throughout the CNS. Mol. Cell Neurosci. 31, 676-684.

Christian, K. M., and Thompson, R. F. (2003). Neural substrates of eyeblink conditioning: acquisition and retention. Learn. Mem. 10, 427-455.

Clark, B. A., and Barbour, B. (1997). Currents evoked in Bergmann glial cells by parallel fibre stimulation in rat cerebellar slices. J. Physiol. 502 (Pt 2), 335-350.

Dermietzel, R., Traub, O., Hwang, T. K., Beyer, E., Bennett, M. V., Spray, D. C., and Willecke, K. (1989). Differential expression of three gap junction proteins in developing and mature brain tissues. Proc. Natl. Acad. Sci. U.S.A. 86, 10148-10152.

Eiberger, J., Kibschull, M., Strenzke, N., Schober, A., Büssow, H., Wessig, C., Djahed, S., Reucher, H., Koch, D. A., Lautermann, J., Moser, T., Winterhager, E., and Willecke, K. (2006). Expression pattern and functional characterization of connexin29 in transgenic mice. Glia 53, 601-611.

Fiacco, T.A., and McCarthy, K. D. (2006). Astrocyte calcium elevations: properties, propagation, and effects on brain signaling. Glia 54, 676-690.

Figiel, M., Allritz, C., Lehmann, C., and Engele, J. (2007). Gap junctional control of glial glutamate transporter expression. Mol. Cell Neurosci. 35, 130-137.

Frisch,C., Theis, M.,DeSouza Silva, M. A., Dere, E., Söhl, G., Teubner, B., Namestkova, K., Willecke, K., and Huston, J. P. (2003). Mice with astrocyte-directed inactivation of connexin 43 exhibit increased exploratory behaviour, impaired motor capacities, and changes in brain acetylcholine levels. Eur. J. Neurosci. 18, 2313-2318.

Garcia, A. D., Doan, N. B., Imura, T., Bush, T. G., and Sofroniew, M. V. (2004). GFAP-expressing progenitors are the principal source of constitutive neurogenesis in adult mouse forebrain. Nat. Neurosci. 7, 1233-1241.

Giaume, C., and McCarthy, K. D. (1996). Control of gap-junctional communication in astrocytic networks. Trends Neurosci. 19, 319-325.

Goldberg, G. S., Lampe, P. D., and Nicholson, B. J. (1999). Selective transfer of endogenous metabolites through gap junctions composed of different connexins. Nat. Cell Biol. 1, 457-459.

Grosche, J., Kettenmann, H., and Reichenbach, A. (2002). Bergmann glial cells form distinct morphological structures to interact with cerebellar neurons. J. Neurosci. Res. 68 , 138-149.

Haan, E. A., Boss, B. D., and Cowan, W. M. (1982). Production and characterization of monoclonal antibodies against the "brain-specific" proteins 14-3-2 and S-100.Proc. Natl. Acad. Sci. U.S.A. 79, 7585-7589.

Haas, B., Schipke, C. G., Peters, O., Söhl, G., Willecke, K., and Kettenmann, H. (2006). Activity-dependent ATPwaves in the mouse neocortex are independent from astrocytic calcium waves. Cereb. Cortex 16, 237-246.

Hansson, E., Muyderman, H., Leonova, J., Allansson, L., Sinclair, J., Blomstrand, F., Thorlin, T., Nilsson, M., and Rönnbäck, L. (2000). Astroglia and glutamate in physiology and pathology: aspects on glutamate transport, glutamate-induced cell swelling and gap-junction communication. Neurochem. Int. 37, 317-329.

Hughes, E. G., Maguire, J. L., McMinn, M. T., Scholz, R. E., and Sutherland, M. L. (2004). Loss of glial fibrillary acidic protein results in decreased glutamate transport and inhibition of PKA-induced EAAT2 cell surface trafficking. Brain Res. Mol. Brain Res. 124, 114-123.

Iacobas, D. A., Iacobas, S., and Spray, D. C. (2007). Connexin-dependent transcellular transcriptomic networks in mouse brain. Prog. Biophys. Mol. Biol. 94, 169-185.
Iacobas, D. A., Iacobas, S., UrbanMaldonado, M., Scemes, E., and Spray, D. C. (2008). Similar transcriptomic alterations in Cx43 knockdown and knockout astrocytes. Cell Commun. Adhes. 15, 195-206.

Ito, M. (2001). Cerebellar long-term depression: characterization, signal transduction, and functional roles. Physiol. Rev. 81, 1143-1195.

Kettenmann, H., and Schipke, C. G. (2004) Calcium signaling in glia. In Glial $<->$ Neuronal Signaling, G. I. Hatton and V. Parpura, eds (Boston/Dordrecht/ London, Kluwer Academic Publishers), pp. 297-321.

Koekkoek, S. K., Yamaguchi, K., Milojkovic, B. A., Dortland, B. R., Ruigrok, T. J., Maex, R., De Graaf, W., Smit, A. E., VanderWerf, F., Bakker, C. E., Willemsen, R., Ikeda, T., Kakizawa, S., Onodera, K., Nelson, D. L., Mientjes, E., Joosten, M., De Schutter, E., Oostra, B. A., Ito, M., and De Zeeuw, C. I. (2005). Deletion of FMR1 in Purkinje cells enhances parallel fiber LTD, enlarges spines, and attenuates cerebellar eyelid conditioning in Fragile X syndrome. Neuron 47, 339-352.

Kwon, C. H., Zhu, X., Zhang, J., Knoop, L. L., Tharp, R., Smeyne, R. J., Eberhart, C. G., Burger, P. C., and Baker, S. J. (2001). Pten regulates neuronal soma size: a mouse model of Lhermitte-Duclos disease. Nat. Genet. 29, 404-411.

Landry, C. F., Ivy, G. O., Dunn, R. J. Marks, A., and Brown, I. R. (1989). Expression of the gene encoding the beta-subunit of S-100 protein in the developing rat brain analyzed by in situ hybridization. Brain Res. Mol. Brain Res. 6, 251-262.

Lin, J. H., Lou, N., Kang, N., Takano, T., Hu, F., Han, X., Xu, Q., Lovatt, D., Torres, A., Willecke, K., Yang, J., Kang, J., and Nedergaard, M. (2008) A central role of connexin 43 in hypoxic preconditioning. J. Neurosci. 28, 681-695.

Lopez-Bayghen, E., Rosas, S., Castelan, F., and Ortega, A. (2007). Cerebellar Bergmann glia: an important model to study neuron-glia interactions. Neuron Glia Biol. 3, 155-167.

Manthey, D., Banach, K., Desplantez, T., Lee, C. G., Kozak, C. A., Traub, O., Weingart, R., and Willecke, K. (2001). Intracellular domains of mouse connexin26 and -30 affect diffusional and electrical properties of gap junction channels. J. Membr. Biol. 181 137-148.

Mauk, M. D., and Buonomano, D. V. (2004). The neural basis of temporal processing. Annu. Rev. Neurosci. 27, 307-340.
Metea, M. R., and Newman, E. A. (2006). Calcium signaling in specialized glial cells. Glia 54, 650-655.

Müller, T., Möller, T., Neuhaus, J., and Kettenmann, H. (1996). Electrical coupling among Bergmann glial cells and its modulation by glutamate receptor activation. Glia 17, 274-284.

Nagy, J. I., Patel, D., Ochalski, P. A., and Stelmack, G. L. (1999). Connexin30 in rodent, cat and human brain: selective expression in gray matter astrocytes, co-localization with connexin 43 at gap junctions and late developmental appearance. Neuroscience 88, 447-468.

Nagy, J. I., Li, X., Rempel, J., Stelmack, G., Patel, D., Staines, W. A., Yasumura, T. and Rash, J. E. (2001). Connexin26 in adult rodent central nervous system: demonstration at astrocytic gap junctions and colocalization with connexin30 and connexin43. J. Comp. Neurol. 441, 302-323.

Nakase, T., Sohl, G., Theis, M., Willecke, K., and Naus, C. C. (2004). Increased apoptosis and inflammation after focal brain ischemia in mice lacking connexin43 in astrocytes. Am. J. Pathol. 164, 2067-2075.

Nishiyama, H., Knopfel, T., Endo, S., and Itohara, S. (2002). Glial protein S100B modulates long-term neuronal synaptic plasticity. Proc. Natl. Acad. Sci. U.S.A. 99, 4037-4042.

Palay, S. L., and Chan-Palay, V. (1974) Cerebellar Cortex - Cytology and Organization. Berlin, Springer.

Ransom, B. R., and Ye,Z. (2005) Gap junctions and hemichannels. In Neuroglia, H. Kettenmann and B. R. Ransom, eds (New York, Oxford University Press), pp. 177-189.

Reaume,A.G., de Sousa, P.A., Kulkarni, S., Langille, B. L., Zhu, D., Davies, T. C., Juneja, S. C., Kidder, G. M., and Rossant, J. (1995). Cardiac malformation in neonatal mice lacking connexin43. Science 267, 1831-1834.

Rothstein, J. D., Dykes-Hoberg, M., Pardo, C. A., Bristol, L. A., Jin, L., Kuncl, R. W., Kanai, Y., Hediger, M. A., Wang, Y., Schielke, J. P., and Welty, D. F. (1996). Knockout of glutamate transporters reveals a major role for astroglial transport in excitotoxicity and clearance of glutamate. Neuron 16, 675-686.

Sakatani, S., Seto-Ohshima, A., Itohara, S., and Hirase, H. (2007). Impact of S100B on local field potential patterns in anesthetized and kainic acidinduced seizure conditions in vivo. Eur. J. Neurosci. 25, 1144-1154.

Sakatani, S., Seto-Ohshima, A., Shinohara, Y., Yamamoto, Y., Yamamoto, H., Itohara, S., and Hirase, H. (2008). Neural-activity- 
dependent release of S100B from astrocytes enhances kainate-induced gamma oscillations in vivo. J. Neurosci. 28, 10928-10936.

Shibuki, K., Gomi, H., Chen, L., Bao, S., Kim, J. J., Wakatsuki, H., Fujisaki, T., Fujimoto, K., Katoh, A., Ikeda, T., Chen, C., Thompson, R. F., and Itohara, S. (1996). Deficient cerebellar long-term depression, impaired eyeblink conditioning, and normal motor coordination in GFAP mutant mice. Neuron 16, 587-599.

Spacek, J. (1985). Three-dimensional analysis of dendritic spines. III. Glial sheath. Anat. Embryol. (Berl.) 171, 245-252.

Tanaka, M., Yamaguchi, K., Tatsukawa, T., Chieko, N., Nishiyama, H., Theis, M., Willecke, K., and Itohara, S. (2008). Lack of connexin43-mediated Bergmann glial gap junctional coupling does not affect cerebellar longterm depression, motor coordination, or eyeblink conditioning. Front. Behav. Neurosci. 2, 1.

Theis, M., de Wit, C., Schlaeger, T. M., Eckardt, D., Krüger, O., Döring, B.,
Risau, W., Deutsch, U., Pohl, U., and Willecke, K. (2001). Endotheliumspecific replacement of the connexin43 coding region by a lac $Z$ reporter gene. Genesis 29, 1-13.

Theis, M., Jauch, R., Zhuo, L., Speidel, D., Wallraff, A., Döring, B., Frisch, C., Söhl, G., Teubner, B., Euwens, C., Huston, J., Steinhäuser, C., Messing, A., Heinemann, U., and Willecke, K. (2003). Accelerated hippocampal spreading depression and enhanced locomotory activity in mice with astrocyte-directed inactivation of connexin43. J. Neurosci. 23, 766-776.

Van Eldik, L. J., Ehrenfried, B., and Jensen, R. A. (1984). Production and characterization of monoclonal antibodies with specificity for the $S 100$ beta polypeptide of brain S100 fractions. Proc. Natl. Acad. Sci. U.S.A. 81, 6034-6038.

Wallraff, A., Köhling, R., Heinemann, U. Theis, M., Willecke, K., and Steinhäuser, C. (2006). The impact of astrocytic gap junctional coupling on potassium buffering in the hippocampus. J. Neurosci. 26 , 5438-5447.

Watase, K., Hashimoto, K., Kano, M. Yamada, K., Watanabe, M., Inoue, Y., Okuyama, S., Sakagawa, T., Ogawa, S., Kawashima, N., Hori, S., Takimoto, M. Wada, K., and Tanaka, K. (1998). Motor discoordination and increased susceptibility to cerebellar injury in GLAST mutant mice. Eur. J. Neurosci. 10, 976-988.

Weber, P. A., Chang, H. C., Spaeth, K. E., Nitsche, J. M., and Nicholson, B. J. (2004). The permeability of gap junction channels to probes of different size is dependent on connexin composition and permeant-pore affinities. Biophys. J. 87, 958-973.

Wiencken-Barger, A. E., Djukic, B., Casper, K. B., and McCarthy, K. D. (2007). A role for Connexin43 during neurodevelopment. Glia 55 675-686.

Yamada, K., and Watanabe, M. (2002). Cytodifferentiation of Bergmann glia and its relationship with Purkinje cells. Anat. Sci. Int. 77, 94-108.
Zhuo, L., Theis, M., Alvarez-Maya, I., Brenner, M., Willecke, K., and Messing, A. (2001). hGFAP-cre transgenic mice for manipulation of glial and neuronal function in vivo. Genesis 31, 85-94.

Conflict of Interest Statement: The authors declare that the research was conducted in the absence of any commercial or financial relationships that could be construed as a potential conflict of interest.

Received: 18 September 2008; accepted: 10 November 2008; published: 15 December 2008.

Citation: Front. Neurosci. (2008) 2, 2:225

233. doi: 10.3389/neuro.01.038.2008

Copyright: (c) 2008 Tanaka, Yamaguchi, Tatsukawa, Theis, Willecke and Itohara. This is an open-access article subject to an exclusive license agreement between the authors and the Frontiers Research Foundation, which permits unrestricted use, distribution, and reproduction in any medium, provided the original authors and source are credited. 